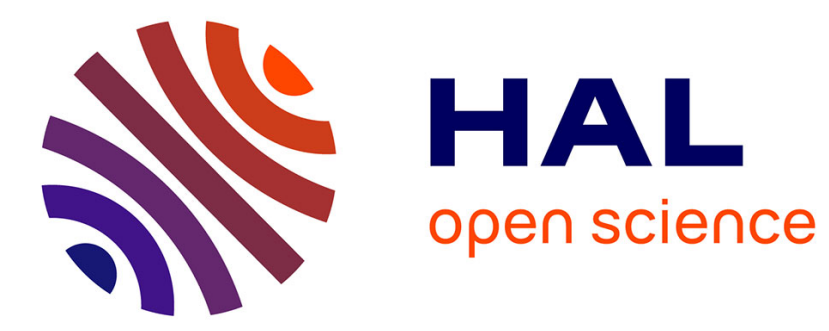

\title{
The Neuroscience of Stigma and Stereotype Threat
}

\author{
Belle Derks, Michael Inzlicht, Sonia Kang
}

\section{To cite this version:}

Belle Derks, Michael Inzlicht, Sonia Kang. The Neuroscience of Stigma and Stereotype Threat. Group Processes and Intergroup Relations, 2008, 11 (2), pp.163-181. 10.1177/1368430207088036 . hal00571682

\section{HAL Id: hal-00571682 \\ https://hal.science/hal-00571682}

Submitted on 1 Mar 2011

HAL is a multi-disciplinary open access archive for the deposit and dissemination of scientific research documents, whether they are published or not. The documents may come from teaching and research institutions in France or abroad, or from public or private research centers.
L'archive ouverte pluridisciplinaire HAL, est destinée au dépôt et à la diffusion de documents scientifiques de niveau recherche, publiés ou non, émanant des établissements d'enseignement et de recherche français ou étrangers, des laboratoires publics ou privés. 


\title{
The Neuroscience of Stigma and Stereotype Threat
}

\author{
Belle Derks \\ Leiden University \\ Michael Inzlicht and Sonia Kang \\ University of Toronto
}

\begin{abstract}
This article reviews social neuroscience research on the experience of stigma from the target's perspective. More specifically, we discuss several research programs that employ electroencephalography, event-related potentials, or functional magnetic resonance imaging methods to examine neural correlates of stereotype and social identity threat. We present neuroimaging studies that show brain activation related to the experience of being stereotyped and ERP studies that shed light on the cognitive processes underlying social identity processes. Among these are two projects from our own lab. The first project reveals the important role of the neurocognitive conflict-detection system in stereotype threat effects, especially as it pertains to stereotype threat 'spillover'. The second project examines the role of automatic ingroup evaluations as a neural mediator between social identity threats and compensatory ingroup bias. We conclude with a discussion of the benefits, limitations, and unique contributions of social neuroscience to our understanding of stigma and social identity threat.
\end{abstract}

KEYWORDS EEG, ERP, social identity, social neuroscience, stereotype threat

Over the years, methodological and technological advances have allowed social psychologists to reduce their reliance on explicit self-report measures of people's emotions, attitudes, and motivations. The movement within the field has been toward a focus on implicit measurements, providing for a more accurate and unbiased assessment of important psychological phenomena. The recent introduction of methods and technology from cognitive neuroscience affords social psychologists yet another theoretical advancement; we are now able to systematically test predictions related to the mechanisms underlying social psychological processes. This merge of social psychology and neuroscience, social neuroscience, has led to important new insights into the cognitive processes and neural mechanisms underlying intergroup phenomena such as categorization, prejudice, and stereotyping. For example, the mechanisms underlying automatic processes that were previously difficult or impossible to identify can now be studied with neural

\footnotetext{
$\overline{\text { Author's note }}$

Address correspondence to Belle Derks, Leiden University, Institute for Psychological

Research, Social and Organizational Psychology Unit, P.O. Box 9555, 2300 RB Leiden, the Netherlands [email: derks@fsw.leidenuniv.nl]
} 
techniques like functional magnetic resonance imaging (fMRI) and electroencephalography (EEG). Neuroscience techniques allow us to explore the role of specific neural regions and systems in complex social psychological phenomena such as person perception and racial bias, thereby improving our understanding of these phenomena by integrating with what is already known about these specific brain regions from neuroscience research (see Ochsner \& Lieberman, 2001, for a primer on social cognitive neuroscience). In turn, social neuroscience informs the field of cognitive neuroscience as a whole by enriching the current body of knowledge with new insights into the intricacies of complex social behaviors and processes.

The past few years in particular have seen an explosion of studies using the social neuroscience approach. As this Special Issue attests, work on stereotyping and prejudice is no exception. EEG and fMRI methods, for example, have been used in the area of person perception to study the hypothesized relationship between automatic and controlled processes (e.g. Bartholow, Dickter, \& Sestir, 2006; Cunningham et al., 2004). To this point, however, most work on the social neuroscience of intergroup processes has focused on the perpetrator's point of view, focusing, for example, on the mental processes and brain regions that are activated when people employ stereotypes to perceive and interpret their social world (see for examples Amodio, Devine, \& Harmon-Jones, 2007; Bartholow et al., 2006; Cunningham et al., 2004; Hart et al., 2000; Ito, Willadsen Jensen, \& Correll, 2007; Phelps et al., 2000; Richeson et al., 2003; Wheeler \& Fiske, 2005). In contrast, surprisingly little social neuroscience research has focused on the target's point of view. Given social neuroscience's role in advancing research on stereotyping and prejudice, it is clear that neuroscience techniques could also advance theory and research on the target's perspective. That is, social neuroscience has great potential in fostering a more comprehensive and integrated understanding of what it means and how it feels to belong to a stigmatized group.

In this article, we review the existing social neuroscience research on stigma and stereotype threat. We begin by discussing the effects of prejudice on targets, including stereotype threat effects and the use of coping mechanisms to protect social identity. Then, we describe how these phenomena can be studied with social neuroscience techniques. Finally, we examine the limitations and benefits of this work and discuss the value of social neuroscience in relation to more traditional measures. Rather than offering a comprehensive analysis of research on stereotype threat (see Shapiro \& Neuberg, 2007; Steele, Spencer, \& Aronson, 2002), this article offers a glimpse into recent neuroscience research emerging in the field of stigma, detailing how tools borrowed from neuroscience and psychophysiology can inform our understanding of the target's perspective. We begin our discussion by providing a selective review of stereotype and social identity threat.

\section{Stereotype and social identity threat: A brief review}

\section{Stereotype threat defined}

Stereotype threat has become one of the most vigorously explored topics of the past decade in social psychology, with research on the topic greeted with much interest within academic psychology and among members of the public alike. The original Steele and Aronson (1995) article is now considered a modern classic (Fiske, 2003), and has been cited well over 600 times $^{1}$. Part of the enthusiasm stems from the fact that the theory of stereotype threat offers a situational interpretation for the long-lasting and seemingly intractable debate over the source of group differences in academic and cognitive performance. This explanation avoids the nature vs. nurture trap, by suggesting that situations themselves can bring about group differences when threats are 'in the air' (Steele, 1997).

Stereotype threat is a situational predicament where individuals are at risk, by dint of their actions or behaviors, of confirming negative stereotypes about their group (Steele \& Aronson, 1995). It is the resulting sense that one might be judged or treated in terms of a negative stereotype. In their original article, 
Steele and Aronson (1995) suggested that because African Americans are well aware of the negative stereotypes impugning their intellectual ability, whenever they are in a situation requiring them to display said ability, they fear confirming the stereotype, a process which could interfere with optimal performance. In support of their hypotheses, their experiments indicated that African American college students underperformed when stereotypes about their group became salient, for example, when they took a 'diagnostic' test of academic ability or when they indicated their race on a demographic survey prior to taking a test.

A speech given by Lawrence Summers, Harvard University's former president, in early 2005 illustrates that women, too, are exposed to negative stereotypes. In this speech, Summers claimed that women lack innate ability in math and science, and that this accounts for why so few of them are to be found-as either students or professors-in math and science classrooms (see Dar-Nimrod \& Heine, 2006). Like with African Americans, these negative beliefs hurt and can lead women to feel threatened every time they perform a task that tries their math and science ability. In an initial set of studies, Spencer, Steele, and Quinn (1999) illustrated that highly capable women underperformed on a math test when they thought the test could reveal 'gender differences in ability' compared to women who thought it was 'gender-neutral'. Importantly, others have shown that subtle manipulations can also activate stereotypes and thus interfere with performance, for example, changing the gender composition of a group (Inzlicht, Aronson, Good, \& McKay, 2006; Inzlicht \& Ben-Zeev, 2000), manipulating the gender of a test administrator (Marx \& Roman, 2002), or even exposing women to sexist advertisements (Davies, Spencer, Quinn, \& Gerhardstein, 2002). As an antidote to President Summers's biological explanation, these studies suggest that one reason women are missing from science is the situational predicament of stereotype threat.

In the years since the publication of Steele and Aronson's article, many articles have followed and documented the generalizability of the stereotype threat effect to a broad array of groups and domains of activity, both in the real world and in the lab. Studies have observed the effect of stereotype threat on performance of women on tests of political knowledge (McGlone, Aronson, \& Kobrynowicz, 2006), of Latinos (Gonzales, Blanton, \& Williams, 2002), and of children of low socioeconomic status on tests of intelligence (Croizet \& Claire, 1998). However, stereotype threat does not exclusively affect members of traditionally devalued or marginalized groups; indeed, even members of non-stigmatized groups can experience stereotype threat. Studies have shown stereotype threat effects with Whites on tests of athletic ability (e.g. Beilock, Jellison, Rydell, McConnell, \& Carr, 2006; Stone, Lynch, Sjomeling, \& Darley, 1999), tests of math ability (Aronson et al., 1999), or tests of racial bias (Frantz, Cuddy, Burnett, Ray, \& Hart, 2004), as well as with psychology students on tests of general knowledge (e.g. Seibt \& Förster, 2004). Finally, although there is some controversy over whether stereotype threat has any impact outside of the laboratory (Cullen, Hardison, \& Sackett, 2004; Stricker \& Ward, 2004), recent evidence suggests that it had an effect in state middle-school exams in Texas (Good, Aronson, \& Inzlicht, 2003) and in elementary school grades in Connecticut (Cohen, Garcia, Apfel, \& Master, 2006).

The consequence of stereotype threat on performance, then, is widely documented, with well over 100 separate studies examining performance deficits (Davies, Spencer, \& Steele, 2005). In contrast, very few studies have gone beyond performance to examine some of the other important consequences of stereotype threat. More recently, however, researchers have recognized this omission and started addressing this crucial subject. Work coming out of our own lab, as well as that of others (e.g. Beilock, Rydell, \& McConnell, 2007), has now indicated that stereotype threat can 'spillover' and affect behaviors and decisions in domains unrelated to the threatening stereotype. We have found, for example, that when female students and students belonging to visible minority groups became aware their actions could confirm negative stereotypes about their 
gender and ethnic groups, they had a more difficult time maintaining their attention, physically exerting themselves, suppressing their appetites, and making rational judgments and decisions (Inzlicht, Kang, \& Fortune, 2008; Inzlicht, McKay, \& Aronson, 2006). Other work has concentrated on the effects of stereotype threat on the self-concept. Some research has suggested that stereotype threat can lead to self-uncertainty about one's abilities and one's belonging in a specific setting (Aronson \& Inzlicht, 2004; Walton \& Cohen, 2007), reducing aspirations in stereotyped domains (Davies et al., 2005), while other research indicates that it can affect the way individuals relate to and identify with their own ingroup (e.g. Pronin, Steele, \& Ross, 2004). Moreover, research studying how stigmatized people cope with stereotype threat shows that chronic threats to social identity can lead them to disengage from domains in which their group is negatively stereotyped (Major \& Schmader, 1998; Major, Spencer, Schmader, Wolfe, \& Crocker, 1998; Osborne, 1995), and compensate for group devaluation by claiming their group's superiority in other performance domains (Derks, Van Laar, \& Ellemers, 2006, 2007). The main point here is that stereotype threat can affect more than just performance, a point to which we will return when describing some of our new lab studies.

\section{Expansion and refinement}

In recent years, theorists have both expanded and refined the concept of stereotype threat. Although stereotype threat is quite pervasive, it is but one form of social identity threat (Steele et al., 2002), a situational predicament occurring when individuals become fearful that their social category is devalued by others (Tajfel \& Turner, 1986; see also Crocker \& Major, 1989). People whose social identity is threatened are not only worried about what negative stereotypes say about them, but also about what they say about groups with which they belong and identify (Tajfel \& Turner, 1986). People may be threatened by negative stereotypes about their group, but they may also be threatened when they suspect that their social identity can put them at risk for social devaluation, exclusion, and biased treatment. This is a broader conception of threat because it includes any situation that contains the possibility of being marginalized, including not only when stereotypes are 'in the air', but also when cues in the environment send messages that one's social identity is not welcome.

In any given setting, a person can come to realize that they could be devalued and discriminated against because of their social identity. This awareness could originate from a person's perceptions of how members of their group are generally treated (Mendoza Denton, Downey, Purdie, Davis, \& Pietrzak, 2002) or from cues in the environment that raise the possibility of such devaluation (Ellemers, Spears, \& Doosje, 2002; Murphy, Steele, \& Gross, 2007). Regardless of the source of realization, the person might become vigilant to the possibility of identity threat and sensitive to the cues communicating that their group's stigmatized social status may be relevant in the immediate situation (Kaiser, Vick, \& Major, 2006). Some settings provide few cues that stereotypes and prejudice are relevant and thus result in individuals experiencing little or no threat to their social identities. These 'identity-safe' environments assure individuals that their social identities are valued and pose no barrier (Davies, et al., 2005). Other situations, however, are less hospitable and can become identity threatening by dint of cues within them. A casual chat in one's dorm room, for example, may become threatening when a first-generation college student realizes that all his roommates' parents are college graduates and highly paid professionals. When people are uncertain of their standing, watchful for stigma-relevant cues, and find themselves in just such an inhospitable environment, the process of social identity threat is set off.

At the same time that theorists have elaborated upon the concept of threat, others have tried to refine and categorize the types of threat, moving the field from social identity threat to social identity threats. In a recent review of the literature, Shapiro and Neuberg (2007) suggested that stereotype threat actually means different things to different researchers because they often use stereotype threat as an umbrella concept 
without articulating the subconcepts that define it. To correct for this, Shapiro and Neuberg proposed a multi-threat framework whereby there is not simply a single stereotype threat, but rather six qualitatively distinct stereotype threats. Specifically, negative stereotypes can lead individuals to experience different types of threats that arise from the intersection of two dimensions: the target of the threat (the self/one's group) and the source of the threat (the self/outgroup others/ingroup others). So, for example, someone could be threatened if they worry that the stereotype is true of them personally or true of their group; they could worry that outgroups see them as stereotypic or see their group as stereotypic; and they could worry that ingroups see them as stereotypic or their own group as stereotypic (e.g. Inzlicht \& Ben Zeev, 2003; Marx, Stapel, \& Muller, 2005; Quinn, Kahng, \& Crocker, 2004; Schmader, 2002). Similarly, Branscombe and colleagues (Branscombe, Ellemers, Spears, \& Doosje, 1999) defined four different types of social identity threat. People can experience threat because their group is devalued (value threat), because they are categorized as members of a group to which they do not want to belong (categorization threat), because their group lacks distinctiveness from other groups (distinctiveness threat), or because they worry whether they are accepted within their group (acceptance threat). Although there is mounting evidence for many of these forms of social identity threat, it is still unclear how these two models converge and how many forms of threat there actually are. Nevertheless, it is clear that stereotype threat and social identity threat take on more than one form, an articulation of which can help us comprehend one of the more important issues surrounding the threat concept, the issue of mediation.

\section{Mediation and process}

Since the publication of the first empirical paper by Steele and Aronson in 1995, researchers have asked questions about process, mechanism, and mediation; fundamentally asking, 'What is stereotype and social identity threat?' Although there is still much to discover, our understanding of process has improved greatly since those early days. Social identity threat is best thought of as a predicament faced by a person in a situation; given the range of possible situations, groups of people, and types of stereotypes, it should come as no surprise that social identities can be threatened through multiple, interacting pathways. The most prominent of these are the physiological stress response due to increased arousal (Ben Zeev, Fein, \& Inzlicht, 2005; Blascovich, Spencer, Quinn, \& Steele, 2001; O'Brien \& Crandall, 2003; Scheepers \& Ellemers, 2005), negative cognitions that consume executive resources (Beilock et al., 2007; Cadinu, Maass, Rosabianca, \& Kiesner, 2005; Schmader \& Johns, 2003), and self-regulatory changes in the aims of managing thoughts and emotions (Derks et al., 2007; Seibt \& Förster, 2004; Spencer, 2003).

There is support for all of these putative mechanisms, but what has been missing is an understanding of how these mechanisms fit together. Recently, however, Schmader, Johns, and Forbes (in press) have proposed a comprehensive, integrated model of stereotype threat where threat is thought to be produced by three distinct, yet interconnected pathways. Placing executive control as the proximal mediator, the model implicates a physiological stress response, a performance monitoring response, and an affect regulation response. For example, when faced with the possibility of confirming a negative stereotype about their social identity, people may feel anxious and physiologically stressed, they may monitor their performance for what it means for them and their group's reputation, and they may try to suppress and deny these emotions so that others won't think they are admitting defeat. All three of these processes can tax one's limited executive control strength, which are the same cognitive resources needed for intellectual performance. Ultimately, this can result in the intellectual performance deficits seen in studies of stereotype threat.

\section{Limitations}

While we have learned a great deal about stereotype and social identity threat over the years, some 
of the fundamental questions-especially those related to mechanism-have been more difficult to elucidate. Part of this, we suppose, is because of the field's reliance on the measurement of overt behaviors and especially the use of selfreport. Let's take the examination of arousal and anxiety in mediating stereotype threat as one example. Although Steele and Aronson (1995) suggested that threat was mediated by anxiety and emotion in their original paper, multiple attempts to support this proved futile (e.g. Spencer et al., 1999; Stone et al., 1999). This assumption only gained support once researchers started using online measurements of psychophysiology (e.g. Blascovitch et al., 2001) or indirect manipulations of arousal state (e.g. Ben-Zeev et al., 2005). And as we will see below, it gained even more traction once researchers started measuring direct brain activity with the modern tools of neuroscience.

The primary objective of this paper is to highlight the important role that social neuroscience has played-and will soon play-in increasing our appreciation of stereotype and social identity threat. The use of such tools as fMRI, EEG, and event-related potentials (ERP) allows researchers to answer questions concerning underlying processes. Importantly, using a social neuroscience approach-which is characterized by a desire to understand phenomena at the levels of social psychology, cognitive psychology, and neuroscience (Harmon-Jones \& Winkielman, 2007; Ochsner \& Lieberman, 2001) — can further clarify how social identity threat not only affects performance, but also affects behaviors in other domains and the self-concept. Ultimately, by capitalizing on biological concepts and methods, this type of research offers an integrative analysis that can inform and refine theories related to stereotype threat and stigmatization, more broadly (Cacioppo et al., 2007).

\section{Neuroscience research on stigma and social identity threat}

Initially, most social psychological research on prejudice and stereotyping examined functions, characteristics, and consequences for people who use stereotypes and hold prejudiced beliefs (e.g. Gaertner \& Dovidio, 1986; Oskamp, 2000; Zanna \& Olson, 1994). The past two decades, however, have seen a rise in research focusing on how prejudice and stereotyping affect its victims (e.g. Crocker \& Major, 1989; Crocker, Major, \& Steele, 1998; Ellemers, Spears, \& Doosje, 1999; Jost \& Major, 2001; Levin \& Van Laar, 2006; Swim \& Stangor, 1998). Examining the existing social neuroscience research on group processes and intergroup relations reveals a similar trend, with most research focused on people who stereotype others, rather than on the stigmatized themselves (e.g. Amodio et al., 2007; Bartholow \& Dickter, 2007; Ito, Urland, Willadsen Jensen, \& Correll, 2006; Ito et al., 2007; Richeson et al., 2003). The introduction of social neuroscience methods to research on stereotyping from the perpetrator's perspective has yielded insights into the processes that underlie prejudice and racial bias. Likewise, we suspect that bringing a social neuroscience approach to social identity and stereotype threat will lead to similar advancements.

In the review that follows, we discuss four lines of social neuroscience research on the target's perspective. The first consists of two fMRI studies examining neural correlates of stereotype threat, more specifically, showing brain activation related to the experience of being stereotyped. The second is an ERP study examining performance-interfering academic disengagement among African American college students. Finally, the third and fourth research lines are ERP studies from our own lab. The first of these projects reveals the important role of the neurocognitive conflict-detection system in stereotype threat effects, especially as it pertains to stereotype threat spillover into cognitive control. The second project focuses on neural correlates of compensatory ingroup bias, a coping mechanism which may be used to alleviate social identity threat.

\section{Stereotype threat effects examined with fMRI} fMRI enables researchers to non-invasively study brain activity online with an impressive level of spatial resolution. By tracking the movement and use of oxygen in the brain, researchers can identify regions of high or low neural activity, 
and make inferences about the involvement of specific brain regions in cognitive or behavioral processes (Bandettini, Birn, \& Donahue, 2000). Within the field of stigma, fMRI research allows us to see first-hand the relationship between the environment and the brain. This type of work is important, as observations of actual neural consequences of stigma are a step toward understanding the mechanism underlying commonly observed behavioral effects of stigma, for example, performance decrements or disengagement. Two examples of social neuroscience research on stereotype threat examine brain activation of women in normal and stereotype threat conditions (Krendl, Richeson, Kelley, \& Heatherton, 2008; Wraga, Helt, Jacobs, \& Sullivan, 2007).

Using fMRI, Krendl and colleagues (2008) sought to understand the neural basis for women's math performance decrements under stereotype threat. In both the stereotype threat and control conditions, women first completed a baseline measure of math performance; women in the threat condition were then reminded of the negative stereotype regarding women and math performance. Following this, all of the women completed a second measure of math performance. In addition to the classic stereotype threat performance effect (women in the control condition displayed improved math performance over time, women in the stereotype threat condition performed worse over time), the fMRI results shed light upon the underlying mechanisms of this effect.

Not surprisingly, women in the control condition showed increased recruitment of neural regions that have been associated with math learning and performance, including the inferior prefrontal cortex, left inferior parietal cortex, and bilateral angular gyrus (Dehaene, Spelke, Pinel, Stanescu, \& Tsivkin, 1999; Delazer et al., 2003). However, women who had been reminded of their group's supposed math inferiority did not show this enhanced activation in useful, math-related brain regions. Instead, they showed increased activation in the ventral anterior cingulate cortex, an area that has been associated with emotional self-regulation and the processing of affective information and social feedback
(Moran, Macrae, Heatherton, Wyland, \& Kelley, 2006; Somerville, Heatherton, \& Kelley, 2006). These results suggest that stereotype threat affects women's math performance in two ways: first, it disrupts normal recruitment of cognitive areas required for high math performance and, second, it increases the recruitment of areas which allow for the processing and regulation of emotions. These results converge with and, indeed, largely confirm, previous behavioral research (Beilock et al., 2007; Schmader \& Johns, 2003; Schmader et al., in press) suggesting that women perform more poorly under stereotype threat because valuable cognitive resources are spent on emotional regulation instead of on the task at hand. The incremental benefit of the fMRI work here is in the ability to test a behavioral theory at the biological level of action, the brain. This can serve as a springboard for further theory-testing investigations. The fact that these results converge with the behavioral work of others provides consistency across different levels of analysis and organization, an important step toward the broad understanding of any complex phenomenon.

These results were supported and further specified by Wraga and colleagues (2007) in an attempt to link brain activation associated with affective processing and reduced performance under stereotype threat. Although their study focused on a different gender stereotype, namely the negative stereotype concerning women's mental rotation performance, the results show similar consequences of stereotype threat on regions associated with emotion regulation. Female participants were either confronted with a positive stereotype related to women's superior perspective taking skills, a negative stereotype related to women's inferior spatial reasoning abilities, or with no stereotype (control condition). fMRI analyses revealed that women under stereotype threat showed increased activity in areas associated with emotional self-regulation (rostral-ventral anterior cingulate cortex) and social knowledge (right orbital gyrus, Milne \& Grafman, 2001). Not only did this study show increased activation, it showed that this pattern of brain activation actually predicted women's worse performance in spatial rotation. 
Using brain activity to predict actual performance is a crucial step-it allows us to go beyond simply mapping stereotype threat effects in the brain to actually predicting behavior based on differential activation of brain regions, in this case, brain regions associated with cognitive processing and emotion regulation. These two studies contribute to our understanding of stereotype threat effects in two ways. First, by revealing the disrupted brain activity of women under stereotype threat, they provide insight into the mechanism through which stereotype threat can impinge upon women's cognitive performance. As has been noted by others (e.g. Schmader et al., in press), even though stereotype threat is a complex, multi-determined phenomenon, most studies focus on one mediator at a time. The use of a neuroscience approach, however, can provide a more integrated picture: here it shows that threatened women experience reductions in cognitive efficiency and increases in affective processing at the same time. Second, although these studies focused on different gender stereotypes, they both showed increased recruitment of brain areas associated with emotion regulation. This provides evidence that although gender stereotypes vary in content, they set in motion the same detrimental effects at the neural level.

\section{An ERP examination of academic disengagement}

Another neuroscience technique that has been applied to the study of stigma is the ERP technique. ERPs are derived from continuous measures of electrical activity in the brain, EEG, by extracting and averaging short epochs (e.g. 1 second) of data that directly follow an event, for example, the presentation of a stimulus (i.e. stimulus-locked ERP) or a participant's response (response-locked ERP). By averaging over a large number of epochs, background noise in the EEG due to other cognitive processes is cancelled out and one is able to focus precisely on the brain activity of interest. Within the ERP waveform, researchers have identified different components that are described in terms of their polarity (Positive/Negative) and latency (in ms, e.g. P300, N200). Each ERP component reflects one or more information processing module (e.g. categorization, evaluation, etc.). The amplitude of the ERP reflects the degree to which the specific module is engaged, while the latency reflects the speed with which this process is completed (Cacioppo, Crites, Gardner, \& Berntson, 1994).

Forbes, Schmader, and Allen (2008) incorporated ERP measures to understand another consequence of stigma, academic disengagement. Previous research has shown that continued exposure to stereotype threat and chronic social identity threat can lead ethnic minority group members to disengage from their academic performance, thereby preventing poor performance and negative group stereotypes from impinging on their self-worth (Major \& Schmader, 1998; Major et al., 1998). Stigmatized group members can disengage from performance domains by devaluing the importance of academic achievements, and by discounting the diagnosticity of academic performance feedback (Major \& Schmader, 1998). Although domain disengagement alleviates threats to one's social identity, it may also contribute to lower academic performance (Osborne, 1995, 1999; Verkuyten \& Thijs, 2004). Forbes and colleagues (2008) sought to understand the negative effects of academic disengagement from a neural perspective.

In their study, students from ethnic minority groups performed a conflict-monitoring task (the Eriksen Flanker task, Eriksen \& Eriksen, 1974) that was framed either neutrally or as diagnostic of intelligence. Participants then reported the value they attached to academic performance. Next, participants completed the Flanker task while continuous EEG was recorded. In the Flanker task, participants must identify a target stimulus as one of two given letters, say $\mathrm{M}$ or $\mathrm{N}$, while four congruent flanker stimuli (MMMMM), or four incongruent flanker stimuli (NNMNN), are simultaneously presented. Incongruent trials are characterized by greater response conflict and require more self-control.

Performance monitoring on this task was measured by a short-latency response-locked negative wave component of the ERP called the 
error-related negativity (ERN). The amplitude of the ERN is larger after errors than after correct responses, and is therefore interpreted as a neural indicator of performance monitoring and error detection (Gehring, Coles, Meyer, \& Donchin, 1995; Gehring, Goss, Coles, Meyer, \& Donchin, 1993). Forbes et al. showed that the degree to which members of ethnic minority groups devalue academics predicted how much they monitored their own performance on the Flanker task (as indicated by ERN amplitude). This was only the case, however, when the task was framed as diagnostic of intelligence: whereas devaluing the academic domain was unrelated to ERN amplitude when the task was presented neutrally, academic devaluing negatively predicted ERN amplitude when the task was presented as diagnostic of intelligence. This indicates that when minority students no longer care for academic performance, they cease to monitor their performance, especially when negative stereotypes are 'in the air'. Again, the results here converge with other behavioral work (Major \& Schmader, 1998) and provide consistency across different levels of analysis and organization.

\section{Stereotype threat and misregulation of self-control}

As mentioned earlier, negative stereotypes can impair effortful self-regulation and spillover to domains unrelated to threatening stereotypes (Beilock et al., 2007; Inzlicht et al., 2006). But how does stereotype threat spillover? Emerging work from our lab suggests that the neurally based self-control system plays a role (Inzlicht et al., 2008).

According to Baumeister and Heatherton (1996), there are at least two distinct causes for self-control failure: underregulation and misregulation. Underregulation is said to occur when an individual fails to exert selfcontrol because he or she is unwilling or simply unable to do so (i.e. ego-depletion, Muraven \& Baumeister, 2000; Muraven Tice \& Baumeister, 1998). Misregulation, on the other hand, is said to occur when self-control strength is applied in a misguided or counterproductive way such that despite one's best efforts, the desired outcome is not achieved. Distinguishing these processes with traditional behavioral measures is difficult; however, neurophysiological data might help by revealing online brain processes.

In our experiment, we induced stereotype threat by giving our male and female participants a 'diagnostic' math test. We then had participants complete the Stroop color-naming task, a task that requires attentional control and self-regulation (Ellis, Rothbart \& Posner, 2004). To examine whether women under stereotype threat either misregulate or underregulate their self-control compared to men, we measured the amplitude of medial-frontal potentials after participants responded. These medial-frontal waves reflect activation of the preconscious conflict monitoring system and constitute the earliest indication that the conflict monitoring system has detected a mismatch between intended and actual responses or, in essence, selfcontrol failure (Gehring et al., 1993; Falkenstein, Hoormann, Christ, \& Hohnsbein, 2000). In tasks like the Stroop where participants are required to make choices quickly, this waveform can be seen after incorrect responses, but also after correct responses on high-conflict trials (e.g. 'RED' in blue font). They are normally not seen, however, on low-conflict trials (e.g. 'RED' in red font) (Yeung, Botvinick, \& Cohen, 2004).

By examining this ERP after errors and highand low-conflict correct responses, we can determine whether stereotype threat spillover is due to underregulation or misregulation. Recent research suggests that neural mechanisms underlying conflict-monitoring are weakened among underregulated individuals (Inzlicht \& Gutsell, 2007). Therefore, if stereotype threat results in underregulation, neural responses to errors should be dampened. If stereotype threat results in misregulation, neural responses should be heightened whereby everything, even insignificant low-conflict trials, is flagged as attentionworthy.

Our results suggest a role for misregulation. Male participants showed larger waves to incongruent than congruent trials, indicating that they were correctly detecting which trials required their attention. Female participants, 
in contrast, displayed higher amplitude waves overall, ruling out the possibility that they were underregulated. They also displayed higher waves for congruent than incongruent trials. Because these medial-frontal waves indicate that events are of significance and require attention, correction, and strategic adjustment (Bartholow et al., 2005; Holroyd \& Coles, 2002), these results suggest that our female participants were misregulated, such that low conflict events (congruent trials) were unnecessarily reacted to with equal or greater vigilance than high conflict trials (incongruent trials). Importantly, this misregulation, or overregulation of easy lowconflict trials, significantly mediated the effect of stereotype threat on cognitive control on the Stroop task.

The insight gained with this study is that stereotype threat spillover is due to a misregulation of the conflict-monitoring system rather than underregulation. Threatening math settings leave women in a state where their neural systems show increased responsivity to both significant and non-significant events. This supports the assertion that women devote a large amount of effort and resources to control outcomes and attend more carefully to the various consequences of their actions (Jamieson \& Harkins, 2007; Murphy et al., 2007). This heightened, but unnecessary, vigilance might then lead the conflict-monitoring system to be non-optimally responsive to conflict in other domains and ultimately lead to self-control failure later on.

\section{Neurological correlates of compensatory ingroup bias}

In a second project, we examined the underlying neural processes of compensatory forms of ingroup bias (Derks \& Inzlicht, 2008). In addition to the domain devaluing strategy examined by Forbes and colleagues (2008), stigmatized group members can cope with negative stereotypes and social identity threat by explicitly favoring their own group over a higher status outgroup in performance domains unrelated to the negative stereotype (Brewer, 1979; Cadinu \& Cerchioni, 2001; Derks et al., 2007; Ellemers \& Van Rijswijk, 1997; Mummendey \& Schreiber,
1984; Scheepers, Spears, Doosje, \& Manstead, 2006; Tajfel \& Turner, 1986). In an ERP study, we sought to gain more insight into this compensatory ingroup bias by mapping out automatic (ERP) and controlled (self-report) forms of ingroup evaluations.

Researchers examining the relationship between threats to group value and compensatory ingroup bias have often encountered difficulties in measuring social identity threat itself. Most of this research has attempted to assess threat and evaluations of the ingroup with self-report measures of, for example, anxiety, collective self-esteem, or evaluations of the ingroup and outgroup on specific dimensions. However, several researchers have suggested that people under identity threat might be unable, or even unwilling, to accurately report their complex and varied feelings toward their own ingroup (Bettencourt, Miller, \& Hume, 1999; Branscombe et al., 1999; Scheepers \& Ellemers, 2005). Recently, however, researchers have measured social identity threat more reliably by looking at cardiovascular indices of arousal (Blascovich et al., 2001; Scheepers \& Ellemers, 2005). In our study, we assessed group value threat even more specifically with ERP measures that indicate stigmatized group members' automatic (vs. controlled) evaluation of their ingroup and outgroup.

The starting point of our study was ERP research conducted by Ito and her colleagues showing that White individuals automatically evaluate racial ingroup members more positively than racial outgroup members (Ito,Thompson, \& Cacciopo, 2004; Ito \& Urland, 2005; Ito et al., 2006). This research focused on a specific component of the ERP termed the late positive potential (LPP), which is a positive-going deflection that peaks between 350 to $900 \mathrm{~ms}$ after presentation of a stimulus (Donchin, 1981; Goldstein, Spencer, \& Donchin, 2002; Nieuwenhuis, Aston Jones, \& Cohen, 2005). LPP amplitude varies with the degree to which a stimulus is evaluated differently from the context in which it is presented, thus reflecting automatic evaluation of stimuli (Cacioppo et al., 1994). Ito and colleagues (2004) utilized this characteristic of the LPP to measure White 
participants' automatic evaluation of racial ingroup and outgroup members in an 'oddball task'. Results revealed that White faces elicited higher LPPs than Black faces, indicating that within the context of negatively valenced pictures, ingroup faces were seen as more evaluatively incongruent than outgroup faces. Importantly, this automatic form of ingroup bias measured with the LPP was positively related to explicit measures of modern racism.

In our study we adjusted this ERP paradigm to measure how female participants automatically evaluated pictures of men and women when group value threat was present or absent. We hypothesized that automatic evaluations of female targets would be lower when female participants were confronted with negative stereotypes about their group than when they were confronted with positive stereotypes about their group. Moreover, by also administering self-report measures of compensatory ingroup bias, we aimed to show that lower automatic evaluations of the ingroup following a negative stereotype would be related to higher explicit compensatory ingroup bias.

Our results showed that stereotype activation predicted LPP amplitude to female faces. Participants confronted with a negative stereotype showed smaller LPPs to female faces than participants confronted with a positive stereotype. This indicates that in the negative stereotype condition these oddballs stood out less in the negative context. In addition to this 'ingroup devaluation effect', the results also revealed the differences between neural and self-report measures: while implicit ingroup evaluation (as indexed by the LPP) suggested that threatened women maligned their own ingroup, self-report of ingroup evaluation suggested that threatened women favored the ingroup. Moreover, LPP amplitude to female targets was negatively related to this explicit ingroup bias. That is, lower automatic evaluations of the ingroup were associated with higher explicit ingroup bolstering when women were confronted with negative stereotypes about their gender. We suggest that this could be interpreted as an overt compensation attempt (see also Cadinu \& Cerchioni,
2001; Ellemers, Van Dyck, Hinkle, \& Jacobs, 2000; Ellemers \& Van Rijswijk, 1997).

This study presents a new way of measuring a specific form of social identity threat, namely threat to group value (Branscombe et al., 1999). Our results indicate that this type of social identity threat affects the automatic associations women have with their gender group. By measuring people's neural responses to in- and outgroup related stimuli, social identity effects can be assessed more directly than was previously possible with self-report measures. These ERP measurements thus allow us to differentiate the automatic associations group members have with their ingroup from their controlled evaluations of this group. Moreover, by relating the neural measures to controlled reports of compensatory ingroup bias, we not only revealed the differential results obtained with implicit and explicit measures, but also underlined the compensatory nature of reporting ingroup bias.

\section{Strengths and limitations of social neuroscience}

With this review of social neuroscience research on stigma, we highlighted some examples of research using techniques derived from neuroscience to contribute to our understanding of stereotype threat and social identity processes. Although some may argue that it is too early to summarize the social neuroscience work that has taken the target's perspective, this review offers a glimpse of how an integrated, biological approach can further our understanding of complex social psychological phenomena. We conclude this article by discussing the incremental value of social neuroscience in understanding stigma and social identity threat.

The fMRI studies we reviewed (Krendl et al., 2008; Wraga et al., 2007) revealed the patterns of brain activation that result from the experience of stereotype threat. These studies lend support to previous behavioral theories which posited that dealing with the emotions aroused by stereotype threat lead to decrements in cognitive performance. Indeed, these studies showed 
that the experience of stereotype threat leads to heightened activity in emotion-regulation centers of the brain, while simultaneously lowering activation in brain regions associated with high math or spatial performance. Although previous research has shown that stereotype threat increases cardiovascular threat responses (Blascovich et al., 2001) and taxes verbal working memory (Beilock et al., 2007; Schmader \& Johns, 2003), to our knowledge, these are the first studies to document these effects at the same time. Examining stereotype threat with neuroimaging techniques, in other words, offers the chance to measure multiple mechanisms as they occur and interact. This helps achieve a richer understanding of how individuals cope with stereotype or social identity threat.

We also discussed research illustrating how ERP techniques can improve our understanding of stereotype threat spillover effects (Inzlicht, Kang, \& Fortune, 2008). ERP techniques enabled us to measure how women under stereotype threat monitor their performance, revealing that self-control failure under stereotype threat is not a matter of underregulation due to cognitive exhaustion or ego-depletion (Inzlicht \& Gutsell, 2007), but rather misregulation of executive functions that lead women to vigilantly monitor their performance, even on easy tasks where this vigilance is unnecessary. This distinction is crucial as it suggests that the reduction of stereotype threat effects is not a matter of increasing women's motivation or self-control strength, but rather, it is a matter of teaching women to reappraise or reduce their anxiety in order to maintain a normal pattern of attentional regulation (Ben Zeev et al., 2005; Cohen et al., 2006; Martens, Johns, Greenberg, \& Schimel, 2006; Sherman, Kinias, Major, Kim, \& Prenovost, 2007). This ERP paradigm improves our understanding of the effects of inappropriate vigilance as it provides us with a straightforward and clean way to measure different patterns of self-regulation (normal vs. misregulation vs. underregulation) and determine how they relate to actual performance. Thus, ERP techniques offer an opportunity to directly test relationships between self-regulation and performance.
In this review, we also discussed how ERP techniques have been used to study coping strategies used by targets of stereotyping. These measures suggested that when ethnic minority students disengage from the academic domain, they are less likely to automatically monitor their performance in that domain (Forbes et al., 2008). Although previous research had suggested that devaluing would lead to lower performance among stigmatized individuals (Crocker et al., 1998; Steele 1992, 1997), this research further elucidates this process by showing why this is the case. The finding that domain devaluation actually leads to lower performance monitoring provides researchers with an additional tool to examine people's investments in specific performance domains in an implicit way. Being able to study this process outside of participants' awareness can be valuable, for example, when participants are unlikely to correctly report their investment in certain domains due to demand characteristics. Moreover, self-report measures of domain investment can be problematic in studies that focus on changes in domain investment due to experimental manipulation, as it is unclear whether participants have insight into changes in domain investment and are able to report their investment accurately.

In the same vein, our own work (Derks \& Inzlicht, 2008) showed that threats to group value, which is difficult to assess directly using traditional self-report measures, does show up in ERP measures that indicate automatic rather than controlled devaluation of the ingroup. Moreover, we were able to show that automatic ingroup evaluations were negatively correlated with compensatory ingroup bias in response to threat. Although this study affirmed what previous research had already assumed about the mediating role of social identity threat in compensatory ingroup bias, using the LPP to assess automatic evaluation of the ingroup and the outgroup does provide researchers with a new tool to assess the magnitude of social identity threat in different settings. Assessing the automatic association people have with social categories is not easy to do with behavioral measures. This is because even relatively implicit measures of these evaluations, such as the 
Implicit Associations Test (Greenwald, McGhee, \& Schwartz, 1998), require participants to give a response, making it hard to distinguish between automatic and controlled processes on these outcomes (Conrey, Sherman, Gawronski, Hugenberg, \& Groom, 2005). ERP measures enable us to assess implicit associations more reliably, by giving us more direct insight into automatic social identity processes. Being able to measure changes in social identity directly can be valuable in studies examining, for example, which contextual cues elicit identity threat or the effectiveness of experimental manipulations designed to alleviate the negative effects of social identity threat on stigmatized group members.

We believe that social neuroscience gains us insight into social psychological processes by integrating the findings in our own field with that of cognitive neuroscience. In our opinion, this integration is social neuroscience's greatest strength. Social psychological theories can only gain what E. O. Wilson calls consilience when they are explained and described at multiple levels of analysis and found to be consistent with one another (Wilson, 1998; see also Snow, 1959). Only by extending our theories and findings to other social and biological levels of analysis, can we ensure convergence of data and explanation (Cacioppo, 2004). In other words, peering into the brain adds an extra dimension of analysis and offers the possibility of gaining a multilevel, integrative analysis of complex social phenomena, such as stereotype threat.

\section{Limitations and recommendations for future research}

We hope that this review of current social neuroscience stigma research will encourage other social psychologists working on this important topic to consider using social neuroscience in their own research. Research on stereotype threat and social identity protection has sometimes been limited by difficulties in reliably assessing the emotions, cognitions, and motivations of our subjects. Techniques developed in neuroscience can be an additional tool for gaining more direct insight into what goes on in the minds of those who are stigmatized. Although social neuroscience techniques expand our experimental toolbox, one should not conclude that social psychological phenomena are not real until their neural correlates have been identified. Neuroscience techniques are not some 'pipeline' to the mind, offering evidence that is somehow 'better' than behavioral evidence (Kihlstrom, 2006). These techniques have their advantages, but ultimately any explanation will need to address brain and behavior. When deciding to use neurological measures in research, therefore, one should always evaluate whether the same insights could not be gained using simpler measures. One should also be careful of being too easily swayed by activity in the brain. A recent study suggests that people are easily convinced of the veracity of a bad explanation when it is accompanied by irrelevant neuroscientific information (Weisberg, Keil, Goodstein, Rawson, \& Gray, 2008). We hope, however, that the many excellent examples of previous social neuroscience research can inspire stigma researchers to find ways to address their own research questions with this new approach (for examples see Cacioppo et al., 2007; Cacioppo \& Berntson, 2004, 2005; Cacioppo, Visser, \& Pickett, 2006; Harmon-Jones \& Winkielman, 2007).

One often heard criticism in discussions about the usefulness of social neuroscience measurements (especially concerning brain imaging techniques such as fMRI) that social neuroscience is simply a new form of phrenology (Uttal, 2002; but see Landreth \& Richardson, 2004). Although we think that there is much to learn from brain imaging in itself-as it allows us to link social psychological processes to knowledge about specific functions of brain regions-we think it is important for researchers to move beyond simply showing effects on fMRI, EEG, or ERP measures. Instead, we suggest that researchers relate measures of brain functioning to behavioral measures. The field of social neuroscience does not limit itself to questions involving localization and neural systems, but actually provides measures that allow us to directly assess the mediating role of social cognition on behavior. By adopting 
this mediational approach, social psychologists can contribute back to cognitive neuroscience, as results from studies in our field will help to uncover the complex functions of specific brain regions.

\section{Note}

1. According to the ISI Web of Science ${ }^{\mathrm{TM}}$, Steele and Aronson's (1995) article has been cited 609 times as of September 12, 2007.

\section{References}

Amodio, D. M., Devine, P. G., \& Harmon-Jones, E. (2007). Mechanisms for the regulation of intergroup responses: Insights from a social neuroscience approach. In P. Winkielman \& E. Harmon-Jones (Eds.), Social neuroscience: Integrating biological and psychological explanations of social behavior (pp. 353-375). New York: Guilford.

Aronson, J., \& Inzlicht, M. (2004). The ups and downs of attributional ambiguity: Stereotype vulnerability and the academic self-knowledge of African American college students. Psychological Science, 15, 829-836.

Aronson, J., Lustina, M. J., Good, C., Keough, K., Steele, C. M., \& Brown, J. (1999). When White men can't do math: Necessary and sufficient factors in stereotype threat. Journal of Experimental Social Psychology, 35, 29-46.

Bandettini, P. A., Birn, R. M., \& Donahue, K. M. (2000). Functional MRI: Background, methodology, limits, and implementation. In G. G. Berntson, J. T. Cacioppo, \& L. G. Tassinary (Eds.), Handbook of psychophysiology (2nd ed., pp. 978-1014). New York: Cambridge University Press.

Bartholow, B. D., \& Dickter, C. L. (2007). Social cognitive neuroscience of person perception: A selective review focused on the event-related brain potential. In P. Winkielman \& E. HarmonJones (Eds.), Social neuroscience: Integrating biological and psychological explanations of social behavior (pp. 376-400). New York: Guilford.

Bartholow, B. D., Dickter, C. L., \& Sestir, M. A. (2006). Stereotype activation and control of race bias: Cognitive control of inhibition and its impairment by alcohol. Journal of Personality and Social Psychology, 90, 272-287.

Bartholow, B. D., Pearson, M. A., Dickter, C., Sher, K. J., Fabiani, M., \& Gratton, G. (2005). Strategic control and medial frontal negativity: Beyond errors and response conflict. Psychophysiology, 42, 33-42.

Baumeister, R. F., \& Heatherton, T. F. (1996). Self-regulation failure: An overview. Psychological Inquiry, 7, 1-15.

Beilock, S. L., Jellison, W. A., Rydell, R. J., McConnell, A. R., \& Carr, T. H. (2006). On the causal mechanisms of stereotype threat: Can skills that don't rely heavily on working memory still be threatened? Personality and Social Psychology Bulletin, 32, 1059-1071.

Beilock, S. L., Rydell, R. J., \& McConnell, A. R. (2007). Stereotype threat and working memory: Mechanisms, alleviation, and spillover. Journal of Experimental Psychology: General, 136, 256-276.

Ben Zeev, T., Fein, S., \& Inzlicht, M. (2005). Arousal and stereotype threat. Journal of Experimental Social Psychology, 41, 174-181.

Bettencourt, B. A., Miller, N., \& Hume, D. (1999). Effects of numerical representation within cooperative settings: Examining the role of salience in in-group favouritism. British Journal of Social Psychology, 38, 265-267.

Blascovich, J., Spencer, S. J., Quinn, D., \& Steele, C. (2001). African Americans and high blood pressure: The role of stereotype threat. Psychological Science, 12, 225-229.

Branscombe, N. R., Ellemers, N., Spears, R., \& Doosje, B. (1999). The context and content of social identity threat. In N. Ellemers, R. Spears, \& B. Doosje (Eds.), Social identity: Context, commitment, content (pp. 35-58). Oxford UK: Blackwell.

Brewer, M. B. (1979). In-group bias in the minimal intergroup situation: A cognitive-motivational analysis. Psychological Bulletin, 86, 307-324.

Cacioppo, J. T. (2004). Common sense, intuition, and theory in personality and social psychology. Personality and Social Psychology Review, 8, 114-122.

Cacioppo, J. T., Amaral, D. G., Blanchard, J. J., Cameron, J. L., Carter, C. S., Crews, D. et al. (2007). Social neuroscience: Progress and implications for mental health. Perspectives on Psychological Science, 2, 99-123.

Cacioppo, J. T., \& Berntson, G. G. (2004). Essays in social neuroscience. Cambridge, MA: MIT Press.

Cacioppo, J. T., \& Berntson, G. G. (2005). Social neuroscience: Key readings. New York: Psychology Press.

Cacioppo, J. T., Crites, S. L., Gardner, W. L., \& Berntson, G. G. (1994). Bioelectrical echoes from evaluative categorizations: I. A late positive 
brain potential that varies as a function of trait negativity and extremity. Journal of Personality and Social Psychology, 67, 115-125.

Cacioppo, J. T., Visser, P. S., \& Pickett, C. L. (2006). Social neuroscience: People thinking about thinking people. Cambridge, MA: MIT Press.

Cadinu, M. R., \& Cerchioni, M. (2001). Compensatory biases after ingroup threat: 'Yeah, but we have a good personality'. European Journal of Social Psychology, 31, 353-367.

Cadinu, M. R., Maass, A., Rosabianca, A., \& Kiesner, J. (2005). Why do women underperform under stereotype threat? Evidence for the role of negative thinking. Psychological Science, 16, 572-578.

Cohen, G. L., Garcia, J., Apfel, N., \& Master, A. (2006). Reducing the racial achievement gap: A social-psychological intervention. Science, 313, 1307-1310.

Conrey, F. R., Sherman, J. W., Gawronski, B., Hugenberg, K., \& Groom, C. J. (2005).

Separating multiple processes in implicit social cognition: The quad model of implicit task performance. Journal of Personality and Social Psychology, 89, 469-487.

Crocker, J., \& Major, B. (1989). Social stigma and self-esteem: The self-protective properties of stigma. Psychological Review, 96, 608-630.

Crocker, J., Major, B., \& Steele, C. (1998). Social stigma. In D. T. Gilbert, S. T. Fiske, \& G. Lindzey (Eds.), The handbook of social psychology (4th ed., Vol. 2, pp. 504-553). Boston: McGraw-Hill.

Croizet, J. C., \& Claire, T. (1998). Extending the concept of stereotype and threat to social class: The intellectual underperformance of students from low socioeconomic backgrounds. Personality and Social Psychology Bulletin, 24, 588-594.

Cullen, M. J., Hardison, C. M., \& Sackett, P. R. (2004). Using SAT-grade and ability-job performance relationships to test predictions derived from stereotype threat theory. Journal of Applied Psychology, 89, 220-230.

Cunningham, W. A., Johnson, M. K., Raye, C. L., Gatenby, J. C., Gore, J. C., \& Banaji, M. R. (2004). Separable neural components in the processing of Black and White faces. Psychological Science, 15, 806-813.

Dar-Nimrod, I., \& Heine, S. J. (2006). Exposure to scientific theories affects women's math performance. Science, 314, 435.

Davies, P. G., Spencer, S. J., Quinn, D. M., \& Gerhardstein, R. (2002). Consuming images: How television commercials that elicit stereotype threat can restrain women academically and professionally. Personality and Social Psychology Bulletin, 28, 1615-1628.

Davies, P. G., Spencer, S. J., \& Steele, C. M. (2005). Clearing the air: Identity safety moderates the effects of stereotype threat on women's leadership aspirations. Journal of Personality and Social Psychology, 88, 276-287.

Dehaene, S., Spelke, E., Pinel, P., Stanescu, R., \& Tsivkin, S. (1999). Sources of mathematical thinking: Behavioral and brain-imaging evidence. Science, 284, 970-974.

Delazer, M., Domahs, F., Bartha, L., Brenneis, C., Lochy, A., Trieb, T. et al. (2003). Learning complex arithmetic-an fMRI study. Cognitive Brain Research, 18, 76-88.

Derks, B., \& Inzlicht, M. (2008). Neural correlates of compensatory ingroup bias following social identity threat. Unpublished manuscript: Leiden University.

Derks, B., Van Laar, C., \& Ellemers, N. (2006). Striving for success in outgroup settings: Effects of contextually emphasizing ingroup dimensions on stigmatized group members' social identity and performance styles. Personality and Social Psychology Bulletin, 32, 576-588.

Derks, B., Van Laar, C., \& Ellemers, N. (2007). Social creativity strikes back: Improving motivated performance of low status group members by valuing ingroup dimensions. European Journal of Social Psychology, 37, 470-493.

Donchin, E. (1981). Surprise! Surprise? Psychophysiology, 18, 493-513.

Ellemers, N., Spears, R., \& Doosje, B. (Eds.). (1999). Social identity: Context, commitment, content. Oxford, UK: Blackwell.

Ellemers, N., Spears, R., \& Doosje, B. (2002). Self and social identity. Annual Review of Psychology, 53, 161-186.

Ellemers, N., Van Dyck, C., Hinkle, S., \& Jacobs, A. (2000). Intergroup differentiation in social context: Identity needs versus audience constraints. Social Psychology Quarterly, 63, 60-74.

Ellemers, N., \& Van Rijswijk, W. (1997). Identity needs versus social opportunities: The use of group-level and individual-level identity management strategies. Social Psychology Quarterly, 60, 52-65.

Ellis, L. K., Rothbart, M. K., \& Posner, M. I. (2004). Individual differences in executive attention predict self-regulation and adolescent psychosocial behaviors. Annals of the New York Academy of Sciences, 1021, 337-340.

Eriksen, B. A., \& Eriksen, C. W. (1974). Effects of noise letters upon the identification of a 
target letter in a nonsearch task. Perception and Psychophysics, 16, 143-149.

Falkenstein, M., Hoormann, J., Christ, S., \& Hohnsbein, J. (2000). ERP components on reaction errors and their functional significance: A tutorial. Biological Psychology, 51, 87-107.

Fiske, S. T. (2003). The discomfort index: How to spot a really good idea whose time has come. Psychological-Inquiry, 14, 203-208.

Forbes, C. E., Schmader, T., \& Allen, J. J. B. (2008). The role of devaluing and discounting in performance monitoring. Unpublished manuscript, University of Arizona.

Frantz, C. M., Cuddy, A. J. C., Burnett, M., Ray, H., \& Hart, A. (2004). A threat in the computer: The race implicit association test as a stereotype threat experience. Personality and Social Psychology Bulletin, 30, 1611-1624.

Gaertner, S. L., \& Dovidio, J. F. (1986). Prejudice, discrimination, and racism: Problems, progress, and promise. In J. F. Dovidio \& S. L. Gaertner (Eds.), Prejudice, discrimination and racism (pp. 315-332). New York: Academic Press.

Gehring, W. J., Coles, M. G. H., Meyer, D. E., \& Donchin, E. (1995). A brain potential manifestation of error-related processing. In G. Karmos, M. Molnar, V. Csepe, I. Czigler, J. E. Desmedt (Eds.), Perspectives of event-related potentials research. Journal of Electroencephalography and Clinical Neurophysiology (Suppl. 44), 287-296

Gehring, W. J., Goss, B., Coles, M. G. H., Meyer, D. E., \& Donchin, E. (1993). A neural system for error detection and compensation. Psychological Science, 4, 385-390.

Goldstein, A., Spencer, K. M., \& Donchin, E. (2002). The influence of stimulus deviance and novelty on the P300 and novelty P3. Psychophysiology, 39, 781-790.

Gonzales, P. M., Blanton, H., \& Williams, K. J. (2002). The effects of stereotype threat and double-minority status on the test performance of Latino women. Personality and Social Psychology Bulletin, 28, 659-670.

Good, C., Aronson, J., \& Inzlicht, M. (2003). Improving adolescents' standardized test performance: An intervention to reduce the effects of stereotype threat. Journal of Applied Developmental Psychology, 24, 645-662.

Greenwald, A. G., McGhee, D. E., \& Schwartz, J. L. K. (1998). Measuring individual differences in implicit cognition: The implicit association test. Journal of Personality and Social Psychology, 74, 1464-1480.
Harmon-Jones, E., \& Winkielman, P. (2007). Social neuroscience: Integrating biological and psychological explanations of social behavior. New York: Guilford.

Hart, A. J., Whalen, P. J., Shin, L. M., McInerney, S. C., Fischer, H., \& Rauch, S. L. (2000). Differential response in the human amygdala to racial outgroup vs. ingroup face stimuli. Neuroreport: For Rapid Communication of Neuroscience Research, 11, 2351-2355.

Holroyd, C. B., \& Coles, M. G. H. (2002). The neural basis of human error processing: Reinforcement learning, dopamine, and the error-related negativity. Psychological Review, 109, 679-709.

Inzlicht, M., Aronson, J., Good, C., \& McKay, L. (2006). A particular resiliency to threatening environments. Journal of Experimental Social Psychology, 42, 323-336.

Inzlicht, M., \& Ben-Zeev, T. (2000). A threatening intellectual environment: Why females are susceptible to experiencing problem-solving deficits in the presence of males. Psychological Science, 11, 365-371.

Inzlicht, M., \& Ben Zeev, T. (2003). Do highachieving female students underperform in private? The implications of threatening environments on intellectual processing. Journal of Educational Psychology, 95, 796-805.

Inzlicht, M., \& Gutsell, J. N. (2007). Running on empty: Neural signals for self-control failure. Psychological Science, 18, 933-937.

Inzlicht, M., Kang, S., \& Fortune, K. (2008). Stereotype threat spillover: How threats to identify affect eating, decision making, and the brain. Unpublished manuscript, University of Toronto.

Inzlicht, M., McKay, L., \& Aronson, J. (2006). Stigma as ego depletion: How being the target of prejudice affects self-control. Psychological Science, 17, 262-269.

Ito, T. A., Thompson, E., \& Cacioppo, J. T. (2004). Tracking the timecourse of social perception: The effects of racial cues on event-related brain potentials. Personality and Social Psychology Bulletin, 30, 1267-1280.

Ito, T. A., \& Urland, G. R. (2005). The influence of processing objectives on the perception of faces: An ERP study of race and gender perception. Cognitive, Affective and Behavioral Neuroscience, 5, 21-36.

Ito, T. A., Urland, G. R., Willadsen Jensen, E., \& Correll, J. (2006). The social neuroscience of stereotyping and prejudice: Using event-related brain potentials to study social perception. 
In J. T. Cacioppo, P. S. Visser, \& C. L. Pickett (Eds.), Social neuroscience: People thinking about thinking people (pp. 189-212). Cambridge, MA: MIT Press.

Ito, T. A., Willadsen Jensen, E., \& Correll, J. (2007). Social neuroscience and social perception: New perspectives on categorization, prejudice, and stereotyping. In P. Winkielman \& E. HarmonJones (Eds.), Social neuroscience: Integrating biological and psychological explanations of social behavior (pp. 401-421). New York: Guilford.

Jamieson, J.P., \& Harkins, S.G. (2007). Mere effort and stereotype threat performance effects. Journal of Personality and Social Psychology, 93, 544-564.

Jost, J. T., \& Major, B. (2001). The psychology of legitimacy: Emerging perspectives on ideology, justice, and intergroup relations. New York: Cambridge University Press.

Kaiser, C. R., Vick, S. B., \& Major, B. (2006). Prejudice expectations moderate preconscious attention to cues that are threatening to social identity. Psychological Science, 17, 332-338.

Kihlstrom, J. F. (2006). Does neuroscience constrain social-psychological theory? SPSP Dialogue, 21, 26-27.

Krendl, A. C., Richeson, J. A., Kelley, W. M., \& Heatherton, T. F. (2008). The negative consequences of threat: An fMRI investigation of the neural mechanisms underlying women's underperformance in math. Psychological Science, 19, 168-175.

Landreth, A., \& Richardson, R. C. (2004). Localization and the new phrenology: A review essay on William Uttal's the new phrenology. Philosophical Psychology, 17, 107-123.

Levin, S., \& Van Laar, C. (Eds.). (2006). Stigma and group inequality: Social psychological perspectives. Mahwah, NJ: Erlbaum.

Major, B., \& Schmader, T. (1998). Coping with stigma through psychological disengagement. In J. K. Swim \& C. Stangor (Eds.), Prejudice: The target's perspective (pp. 219-241). San Diego, CA: Academic Press.

Major, B., Spencer, S., Schmader, T., Wolfe, C., \& Crocker, J. (1998). Coping with negative stereotypes about intellectual performance: The role of psychological disengagement. Personality and Social Psychology Bulletin, 24, 34-50.

Martens, A., Johns, M., Greenberg, J., \& Schimel, J. (2006). Combating stereotype threat: The effect of self-affirmation on women's intellectual performance. Journal of Experimental Social Psychology, 42, 236-243.
Marx, D. M., \& Roman, J. S. (2002). Female role models: Protecting women's math test performance. Personality and Social Psychology Bulletin, 28, 1183-1193.

Marx, D. M., Stapel, D. A., \& Muller, D. (2005). We can do it: The interplay of construal orientation and social comparisons under threat. Journal of Personality and Social Psychology, 88, 432-446.

McGlone, M. S., Aronson, J., \& Kobrynowicz, D. (2006). Stereotype threat and the gender gap in political knowledge. Psychology of Women Quarterly, 30, 392-398.

Mendoza Denton, R., Downey, G., Purdie, V. J., Davis, A., \& Pietrzak, J. (2002). Sensitivity to status-based rejection: Implications for African American students' college experience. Journal of Personality and Social Psychology, 83, 896-918.

Milne, E., \& Grafman, J. (2001). Ventromedial prefrontal cortex lesions in humans eliminate implicit gender stereotyping. Journal of Neuroscience, 21, 1-6.

Moran, J. M., Macrae, C. N., Heatherton, T. F., Wyland, C. L., \& Kelley, W. M. (2006). Neuroanatomical evidence for distinct cognitive and affective components of self. Journal of Cognitive Neuroscience, 18, 1586-1594.

Mummendey, A., \& Schreiber, H. J. (1984). 'Different' just means 'better': Some obvious and some hidden pathways to in-group favouritism. British Journal of Social Psychology, 23, 363-368.

Muraven, M., \& Baumeister, R. F. (2000). Selfregulation and depletion of limited resources: Does self-control resemble a muscle? Self, 126, 247-259.

Muraven, M., Tice, D. M., \& Baumeister, R. F. (1998). Self-control as limited resource: Regulatory depletion patterns. Journal of Personality and Social Psychology, 74, 774-789.

Murphy, M. C., Steele, C. M., \& Gross, J. J. (2007). Signaling threat: How situational cues affect women in math, science, and engineering settings. Psychological Science, 18, 879-885.

Nieuwenhuis, S., Aston Jones, G., \& Cohen, J. D. (2005). Decision making, the P3, and the locus coeruleus-norepinephrine system. Psychological Bulletin, 131, 510-532.

Nieuwenhuis, S., Ridderinkhof, K.R., Blom, J., Band, G.P.H., \& Kok, A. (2001). Error-related brain potentials are differentially related to awareness of response errors: Evidence from an antisaccade task. Psychophysiology, 38, 752-760.

O’Brien, L. T., \& Crandall, C. S. (2003). Stereotype threat and arousal: Effects on women's math 
performance. Personality and Social Psychology Bulletin, 29, 782-789.

Ochsner, K. N., \& Lieberman, M. D. (2001). The emergence of social cognitive neuroscience. American Psychologist, 56, 717-734.

Osborne, J. W. (1995). Academics, self-esteem, and race: A look at the underlying assumptions of the disidentification hypothesis. Personality and Social Psychology Bulletin, 21, 449-455.

Osborne, J. W. (1999). Unraveling underachievement among African American boys from an identification with academics perspective. Journal of Negro Education, 68, 555-565.

Oskamp, S. (Ed.). (2000). Reducing prejudice and discrimination. Mahwah, NJ: Erlbaum.

Phelps, E. A., O'Connor, K. J., Cunningham, W. A., Funayama, E. S., Gatenby, J. C., Gore, J. C. et al. (2000). Performance on indirect measures of race evaluation predicts amygdala activation. Journal of Cognitive Neuroscience, 12, 729-738.

Pronin, E., Steele, C. M., \& Ross, L. (2004). Identity bifurcation in response to stereotype threat: Women and mathematics. Journal of Experimental Social Psychology, 40, 152-168.

Quinn, D. M., Kahng, S. K., \& Crocker, J. (2004). Discreditable: Stigma effects of revealing a mental illness history on test performance. Personality and Social Psychology Bulletin, 30, 803-815.

Richeson, J. A., Baird, A. A., Gordon, H. L., Heatherton, T. F., Wyland, C. L., Trawalter, S. et al. (2003). An fMRI investigation of the impact of interracial contact on executive function. Nature Neuroscience, 6, 1323-1328.

Scheepers, D., \& Ellemers, N. (2005). When the pressure is up: The assessment of social identity threat in low and high status groups. Journal of Experimental Social Psychology, 41, 192-200.

Scheepers, D., Spears, R., Doosje, B., \& Manstead, A. S. R. (2006). Diversity in in-group bias: Structural factors, situational features, and social functions. Journal of Personality and Social Psychology, 90, 944-960.

Schmader, T. (2002). Gender identification moderates stereotype threat effects on women's math performance. Journal of Experimental Social Psychology, 38, 194-201

Schmader, T., \& Johns, M. (2003). Converging evidence that stereotype threat reduces working memory capacity. Journal of Personality and Social Psychology, 85, 440-452.
Schmader, T., Johns, M., \& Forbes, C. (in press). An integrated process model of stereotype threat effects on performance. Psychological Review.

Seibt, B., \& Förster, J. (2004). Stereotype threat and performance: How self-stereotypes influence processing by inducing regulatory foci. Journal of Personality and Social Psychology, 87, 38-56.

Shapiro, J. R., \& Neuberg, S. L. (2007). From stereotype threat to stereotype threats: Implications of a multi-threat framework for causes, moderators, mediators, consequences, and interventions. Personality and Social Psychology Review, 11, 107-130.

Sherman, D. K., Kinias, Z., Major, B., Kim, H. S., \& Prenovost, M. (2007). The group as a resource: Reducing biased attributions for group success and failure via group affirmation. Personality and Social Psychology Bulletin, 33, 1100-1112.

Snow, C. P. (1959). Two cultures. Cambridge, UK: Cambridge University Press.

Somerville, L. H., Heatherton, T. F., \& Kelley, W. M. (2006). Anterior cingulate cortex responds differentially to expectancy violation and social rejection. Nature Neuroscience, 9, 1007-1008.

Spencer, S. J. (2003). Media images and stereotype threat: How activation of cultural stereotypes can undermine women's math performance. Paper presented at the 4th Annual Meeting of the Society of Personality and Social Psychology, Los Angeles, CA.

Spencer, S. J., Steele, C. M., \& Quinn, D. M. (1999). Stereotype threat and women's math performance. Journal of Experimental Social Psychology, 35, 4-28.

Steele, C. M. (1992). Race and the schooling of Black Americans. Atlantic Monthly, 269, 68-78.

Steele, C. M. (1997). A threat in the air: How stereotypes shape intellectual identity and performance. American Psychologist, 52, 613-629.

Steele, C. M., \& Aronson, J. (1995). Stereotype threat and the intellectual test performance of African Americans. Journal of Personality and Social Psychology, 69, 797-811.

Steele, C. M., Spencer, S. J., \& Aronson, J. (2002). Contending with group image: The psychology of stereotype and social identity threat. In M. P. Zanna (Ed.), Advances in experimental social psychology (Vol. 34, pp. 379-440). San Diego, CA: Academic Press.

Stone, J., Lynch, C. I., Sjomeling, M., \& Darley, J. M. (1999). Stereotype threat effects on black and 
white athletic performance. Journal of Personality and Social Psychology, 77, 1213-1227.

Stricker, L. J., \& Ward, W. C. (2004). Stereotype threat, inquiring about test takers' ethnicity and gender, and standardized test performance. Journal of Applied Social Psychology, 34, 665-693.

Swim, J. K., \& Stangor, C. (Eds.). (1998). Prejudice: The target's perspective. San Diego, CA: Academic Press.

Tajfel, H., \& Turner, J. C. (1986). The social identity theory of intergroup behavior. In $\mathrm{S}$. Worchel \& W. G. Austin (Eds.), The psychology of intergroup relations (pp. 7-24). Chicago: Nelson-Hall.

Uttal, W. R. (2002). Precis of the new phrenology: The limits of localizing cognitive processes in the brain. Netherlands: Kluwer Academic Publishers.

Verkuyten, M., \& Thijs, J. (2004). Psychological disidentification with the academic domain among ethnic minority adolescents in the Netherlands. British Journal of Educational Psychology, 74, 109-125.

Walton, G. M., \& Cohen, G. L. (2007). A question of belonging: Race, social fit, and achievement. Journal of Personality and Social Psychology, 92, 82-96.

Weisberg, D. S., Keil, F. C., Goodstein, J., Rawson, E., \& Gray, J. R. (2008). The seductive allure of neuroscience explanations. Journal of Cognitive Neuroscience, 20, 470-477.

Wheeler, M. E., \& Fiske, S. T. (2005). Controlling racial prejudice: Social-cognitive goals affect amygdala and stereotype activation. Psychological Science, 16, 56-63.

Wilson, E. 0. (1998). Consilience: The unity of knowledge. NewYork: Knopf.

Wraga, M., Helt, M., Jacobs, E., \& Sullivan, K. (2007). Neural basis of stereotype-induced shifts in women's mental rotation performance. Social Cognitive and Affective Neuroscience, 2, 12-19.

Yeung, N., Botvinick, M. M., \& Cohen, J. D. (2004).

The neural basis of error detection: Conflict monitoring and the error-related negativity. Psychological Review, 111, 931-959.

Zanna, M. P., \& Olson, J. M. (Eds.). (1994). The psychology of prejudice: The Ontario symposium (Vol. 7). Hillsdale, NJ: Erlbaum.

\section{Biographical notes}

BELLE DERKS is an assistant professor in social and organization psychology at Leiden University. Her research focuses on the effects of stigma and social identity threat on the wellbeing, performance motivation and mediating physiological responses (EEG, ECG, ICG) of members of socially devalued groups. She was recently awarded the 2007 Social Issues Dissertation Award from the Society for the Psychological Study of Social Issues (SPSSI).

MICHAEL INZLICHT is an assistant professor in the department of psychology at University of Toronto Scarborough. He completed his BSc in anatomical sciences at McGill University, his $\mathrm{PhD}$ in experimental psychology at Brown University, and his postdoctoral fellowship in applied psychology at New York University. He conducts basic research on prejudice, stigma, and selfregulation, and has begun using methods and techniques borrowed from neuroscience and psychophysiology to understand them more fully. He was recently honored by being named the 2006 Louise Kidder Early Career Award recipient.

SONIA KANG is a PhD student in the department of psychology at the University of Toronto. She completed her BSc (Hons) at the University of Alberta. She conducts basic and applied research on the experience of prejudice and discrimination across the lifespan from early childhood to old age. 